\title{
Eicosapentaenoic acid and 3,10 dithia stearic acid inhibit the desaturation of trans-vaccenic acid into cis-9, trans-11-conjugated linoleic acid through different pathways in Caco-2 and T84 cells
}

\author{
Bénédicte Renaville ${ }^{1,2,3}$, Anne Mullen ${ }^{4}$, Fiona Moloney ${ }^{4}$, Yvan Larondelle ${ }^{1}$, Yves-Jacques Schneider ${ }^{2}$ and \\ Helen M. Roche ${ }^{4 *}$ \\ ${ }^{1}$ Laboratoire de Biochimie cellulaire, Institut des Sciences de la Vie, Université catholique de Louvain, Louvain-la-Neuve, Belgium \\ ${ }^{2}$ Unité de Biochimie de la Nutrition, Institut des Sciences de la Vie, Université catholique de Louvain, Louvain-la-Neuve, Belgium \\ ${ }^{3}$ Fisiologia Veterinaria e Nutrizione, Dept Science degli Alimenti, Università degli Studi di Udine, Italy \\ ${ }^{4}$ Nutrigenomics Research Group, Department of Clinical Medicine, Institute of Molecular Medicine, Trinity College Dublin, \\ St James's Hospital, James's Street, Dublin 8, Republic of Ireland
}

(Received 21 June 2005 - Revised 24 November 2005 - Accepted 6 December 2005)

\begin{abstract}
Stearoyl-CoA desaturase (SCD) is a key enzyme that determines the composition and metabolic fate of ingested fatty acids, in particular the conversion of trans-vaccenic acid (TVA) to conjugated linoleic acid (CLA). The present study addressed the hypothesis that intestinal TVA absorption and biotransformation into CLA can be modulated by EPA and 3,10-dithia stearic acid (DSA) via altered SCD mRNA levels and desaturation indices (cis-9, trans-11-CLA:TVA and oleic acid:stearic acid ratios) in Caco-2 and T84 cells, two well-established in vitro models of the human intestinal epithelium. The study determined the effect of acute ( $3 \mathrm{~h}$ with $0.3 \mathrm{~mm}$-EPA or $0.3 \mathrm{~mm}-\mathrm{DSA}$ ) and acute-on-chronic ( 1 week with $0.03 \mathrm{~mm}$-EPA or -DSA, followed by respectively, $0.3 \mathrm{~mm}$-EPA or -DSA for $3 \mathrm{~h}$ ) treatments. In both cell lines, acute EPA treatment did not alter SCD desaturation indices, whereas the acute-on-chronic treatment affected these surrogate markers of SCD activity. This was associated with reduced sterol regulatory-element binding protein-1c and SCD mRNA levels. In contrast, acute and acute-on-chronic DSA treatments significantly reduced SCD desaturation indices without affecting SCD mRNA levels in Caco-2 cells. The present study on intestinal cells shows that the conversion rate of TVA to c9, t11-CLA is affected by other fatty acids present in the diet such as EPA, confirming previous observations in hepatic and mammary cell models.
\end{abstract}

Stearoyl-CoA desaturase: Trans fatty acids: Conjugated linoleic acid

Trans-vaccenic acid (TVA; trans-11-18: 1) is a natural trans fatty acid, found in foods derived from ruminant animals, in particular dairy products, and is formed through biohydrogenation of unsaturated fatty acids by ruminal bacteria (Sommerfeld, 1983; Slattery et al. 2001). TVA is believed to have potential positive effects on health due to its partial metabolic conversion to rumenic acid, the well-known cis-9, trans-11-conjugated linoleic acid (c9, t11-CLA) (Lock et al. 2004). Since TVA is the precursor of CLA, it is important to understand whether its intestinal absorption and metabolism can be modulated by other nutrients (Lin et al. 2004), thus affecting the bio-potency of CLA.

The enzyme responsible for the conversion of TVA to c9, t11-CLA is stearoyl-CoA desaturase (SCD). SCD classically converts stearoyl-CoA into oleoyl-CoA. This enzyme has been studied for a long time, due to this crucial role in regulating the unsaturated:saturated ratio, which in turn influences many cellular functions including the fluidity of the cell membranes (Kim \& Ntambi, 1999). SCD is strongly modulated by nutrients, drugs, environmental factors (for a review, see Ntambi \& Miyazaki, 2004). To our knowledge, from all substances known to act on the $\Delta-9$ desaturation process, only sterculic acid (Lock et al. 2004) has been studied for its effects on the conversion of TVA to c9, t11-CLA. Nutrients, in particular fatty acids, regulate SCD both at the transcription and enzyme activity levels. The half-life of the SCD mRNA can be shortened by the PUFA arachidonic acid (Sessler et al. 1996). The amount of SCD mRNA can also be regulated by several transcription factors, including sterol regulatory-element binding protein-1c (SREBP-1c) and PPAR $\alpha$. So far, SCD is the only gene identified to be under the control of both factors (Nakamura \& Nara, 2002), which is unusual since SREBP-1c regulates lipid synthesis and PPAR $\alpha$ lipid oxidation. 
The present study investigated the effect of EPA and 3,10-dithia stearic acid (DSA) on SCD mRNA levels and intestinal TVA metabolism in two well characterised polarised cell culture systems, Caco- 2 and T84 cells, models of the lipid metabolism in human intestinal epithelial cells (Black et al. $2002 b$ ). EPA, a natural $n$-3 PUFA, is a well-known inhibitor of SCD (Ntambi, 1999). DSA is a fatty acid analogue with sulfur atoms substituting methylene groups in the carbon chain at the third and tenth positions. DSA has been used as SCD inhibitor in 7800 CI Morris hepatoma cells and rat hepatocytes (Hovik et al. 1997). To date, little is known of the mechanism whereby fatty acid inhibitors of SCD modulate TVA metabolism in the gut, which is relevant within the context of TVA and CLA bioavailability, as well as intestinal lipid metabolism. Therefore, the objective of the present study was to understand the interactions between acute $(3 \mathrm{~h})$ and acute-on-chronic ( $3 \mathrm{~h}$ following $7 \mathrm{~d}$ fatty acid pre-treatment) effects of the natural fatty acid EPA $v$. the sulfur-modified fatty acid DSA on SCD mRNA abundance and TVA metabolism.

\section{Materials and methods}

\section{Cell culture}

Several experiments have investigated TVA metabolism in hepatic (Gruffat et al. 2005) and mammary (Loor et al. 2002, 2003; Lin et al. 2004) cells but little is know of its effect in intestinal cells. The intestine is the first organ to be exposed to and metabolise fatty acids; there, fatty acids are metabolised and incorporated into chylomicrons. It plays a key role in determining the exposure of other organs to dietary fatty acids (Black et al. 2002a,b). Therefore, the epithelial cell lines Caco-2 and T84 were chosen as in vitro models of intestinal epithelium, to investigate the effect of EPA and DSA on intestinal TVA metabolism.

The two cell lines were obtained from the European Collection of Animal Cell Cultures (Salisbury, Wiltshire, UK). Caco-2 and T84 cells were grown in a 1:1 mixture of Ham's F12 and Dulbecco's modified Eagle's medium (Sigma, Poole, Dorset, UK), which was supplemented with L-glutamine ( $2 \mathrm{~mm}$; Sigma), penicillin ( $100 \mathrm{U} / \mathrm{ml}$; Sigma), streptomycin $(100 \mathrm{mg} / \mathrm{ml}$; Sigma) and $10 \%$ fetal calf serum (GibcoBRL, Paisley, UK). They were incubated in flasks at $37^{\circ} \mathrm{C}$ in a humidified atmosphere of $5 \% \mathrm{CO}_{2}$ and split using a trypsin-EDTA solution (Sigma). Cells were seeded at a density of $3 \times 10^{5}$ cells per $24 \mathrm{~mm}$ polycarbonate transwell (growth area $4.7 \mathrm{~cm}^{2}$; pore size $0.4 \mu \mathrm{m}$; Costar, High Wycombe, Bucks, UK) and grown for $14 \mathrm{~d}$. Apical and basolateral media were changed once per d during the course of cell growth and development. Cell passages used were between 51 and 52 for Caco- 2 cells and between 48 and 49 for T84 cells.

\section{Experimental design}

The present study was designed to determine the acute $(3 \mathrm{~h})$ and acute-on-chronic ( $3 \mathrm{~h}$ following $7 \mathrm{~d}$ fatty acid pre-treatment) effects of EPA and DSA on TVA metabolism. For clarity, treatment refers to acute effects and supplementation refers to chronic effects of fatty acids.
The acute effects of EPA and DSA (kindly supplied by Professor Spydevold, Oslo, Norway) were determined in Caco-2 and T84 cells that had been grown for $14 \mathrm{~d}$ in standard conditions. For the acute treatment, cells were then incubated for $30 \mathrm{~min}$ with $1 \mathrm{mM}$-taurocholate and $0.3 \mathrm{~mm}$-EPA or DSA, and finally for $3 \mathrm{~h}$ with $1 \mathrm{~mm}$-taurocholate, $0.3 \mathrm{~mm}$-TVA, $0.3 \mathrm{~mm}$-EPA or -DSA before harvesting. These fatty acid concentrations were not toxic and were chosen as possibly physiological on the basis of TVA and EPA dietary intake (Wolff, 1995; Astorg et al., 2004). Taurocholate was used in order to mimic intestinal lumen fatty acids emulsion (Field et al. 2002).

To investigate the acute-on-chronic effect of fatty acid supplementation on cell TVA metabolism, the cells received, after $7 \mathrm{~d}$ of culture in standard conditions, chronic fatty acid supplementation (1 mM-taurocholate and $0.03 \mathrm{~mm}$-EPA or -DSA) for $7 \mathrm{~d}$, followed by $3 \mathrm{~h}$ acute treatment $(1 \mathrm{mM}-$ taurocholate, $0.3 \mathrm{~mm}$-TVA, $0.3 \mathrm{~mm}-\mathrm{EPA}$ or -DSA) before harvesting.

EPA and DSA were stored in ethanol at $-20^{\circ} \mathrm{C}$. Sodium taurocholate was added $(1 \mathrm{~mm})$ in order to make the fatty acids soluble in the media. The fatty acid supplements were added to the apical compartment of the transwells; the basolateral compartment did not receive fatty acid supplementation. This was done to mimic the intestinal epithelium where only the apical surface of enterocytes is exposed to dietary fats.

\section{Cell viability}

The effect of 0.3 or 0.03 mM-EPA, -DSA or -TVA on Caco-2 or T84 cells proliferation was investigated using the Cell Titer 96 Aqueous Non-Radioactive Cell Proliferation Assay and protocol (Promega, Madison, WI, USA). Briefly, cells receiving each fatty acid treatment were seeded in ninety-six-well microtitre plates (Falcon; Becton-Dickinson Labware, Lincoln Park, NJ, USA) at a density of $10^{5}$ cells/well and grown for $24 \mathrm{~h}$. 3-(4,5-Dimethylthiazol-2-yl)-5-(3-carboxymethoxyphenyl)-2-(4-sulfophenyl)-2H-tetrazolium (MTS)-phenazine methosulfate solution $(20 \mu \mathrm{l})$ was added to each well and cells were incubated for $4 \mathrm{~h}$ at $37^{\circ} \mathrm{C}$ before absorbance reading at $490 \mathrm{~nm}$. Results of the MTS proliferation assay of Caco-2 cells and T84 supplemented with 0.03 or $0.3 \mathrm{~mm}$ TVA, -EPA or -DSA are presented in Table 1. ANOVA demonstrated that the treatments used in these experiments did not affect the proliferation of either cell line.

The transepithelial electrical resistance (TER) of Caco-2 and T84 cells growing in the inserts was measured with the Endohm apparatus (World Precision Instruments, Sarasota, FL, USA) at $24 \mathrm{~h}$ intervals. TER increased progressively during approximately 8-10d until confluence, when cells formed high-resistance monolayers with stable TER values of 340 (SEM 93) $\Omega / \mathrm{cm}^{2}$ ( $n$ 48) for T84 cells and 179 (SEM 34) $\Omega / \mathrm{cm}^{2}$ ( $n$ 48) for Caco- 2 cells. In Caco- 2 cells, the supplementations with either EPA or DSA had no significant effect on TER values compared with control cells. TER values of T84 cells supplemented with $0.03 \mathrm{mM}$-EPA or -DSA are presented in Fig. 1. In T84 cells, DSA was associated with a marked decrease of TER compared with cells supplemented with EPA or control cells. 
Table 1. Effect of trans-vaccenic acid (TVA), eicosapentaenoic acid and 3,10-dithia stearic acid (DSA) on cellular proliferation in T84 (passage 48; 105 cells/well) and Caco-2 (passage 51; 100000 cells/well) cells*

(Mean values with their standard errors of four wells per fatty acid treatment)

\begin{tabular}{lcccc}
\hline & \multicolumn{3}{c}{ Proliferation (\% of control) } \\
\cline { 2 - 4 } & \multicolumn{2}{c}{ T84 } & \multicolumn{2}{c}{ Caco-2 } \\
\cline { 2 - 5 } Cell line... & Mean & SEM & Mean & SEM \\
\hline Control & 1.00 & 0.05 & 1.00 & 0.05 \\
TVA (0.03 mM) & 0.95 & 0.07 & 1.04 & 0.03 \\
TVA (0.3 mM) & 1.06 & 0.05 & 1.18 & 0.02 \\
EPA (0.03 mm) & 1.00 & 0.05 & 1.04 & 0.05 \\
EPA (0.3 mM) & 1.06 & 0.02 & 0.93 & 0.07 \\
DSA (0.03 mM) & 1.01 & 0.05 & 1.04 & 0.05 \\
DSA (0.3 mM) & 1.14 & 0.04 & 1.03 & 0.06 \\
\hline
\end{tabular}

* Determined by 3-(4,5-dimethylthiazol-2-yl)-5-(3-carboxymethoxyphenyl)-2-(4-sulfophenyl)- $2 \mathrm{H}$-tetrazolium proliferation assay.

\section{mRNA abundance}

Total RNA was extracted from cells using TriZOL reagent and protocol from Invitrogen (Paisley, UK). The mRNA levels of SCD, PPAR $\alpha$ and SREBP-1c was analysed using Taq-Man quantitative real-time PCR.

RNA $(2 \mu \mathrm{g})$ was treated with RNase-free DNase to remove contaminating genomic DNA (DNAase I Amplification Grade; Invitrogen). After inactivating the DNase by the addition of $1.5 \mu \mathrm{l}$ EDTA $(25 \mathrm{~mm})$ and heating at $65^{\circ} \mathrm{C}$ for $10 \mathrm{~min}$, total RNA was reverse-transcribed for $1 \mathrm{~h}$ at $37^{\circ} \mathrm{C}$ followed by $10 \mathrm{~min}$ at $70^{\circ} \mathrm{C}$ in a $25 \mu \mathrm{l}$ reaction mixture containing $5 \mu \mathrm{l}$ RT buffer (50 mM-Tris-HCl, $75 \mathrm{~mm}-\mathrm{KCl}, 3 \mathrm{~mm}-\mathrm{MgCl}_{2}$, $10 \mathrm{~mm}$-dithiothreitol), $500 \mathrm{ng}$ random primers, $0.4 \mathrm{~mm}$ dNTPs, and 300 units Moloney murine leukaemia virus RT (Promega). Reactions in which Moloney murine leukaemia virus RT was omitted served as negative controls. As a standard, five samples were reverse-transcript; these five samples were pooled after first-strand cDNA synthesis. This standard was serially diluted 1:2 in DNase-free water to generate a standard curve for the PCR analysis. Samples were diluted in diethyl pyrocarbonate-water (Sigma) in order to obtain a final concentration of $20 \mathrm{ng} / \mu \mathrm{l}$.

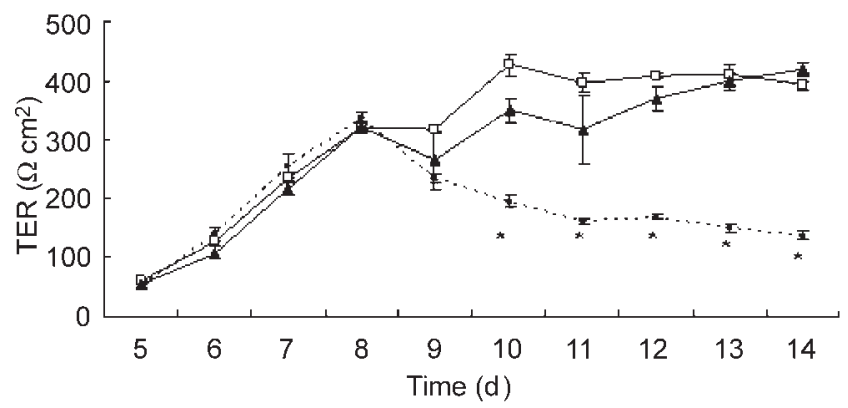

Fig. 1. Transepithelial electrical resistance (TER) of T84 cells grown in media unsupplemented (control; $-\mathbf{\Delta}^{-}$) or supplemented with EPA (-口-) or 3,10-dithia stearic acid (DSA; $\cdots \bullet \cdot\left(0.03 \mathrm{~mm}\right.$; passage $48 ; 3 \times 10^{5}$ cells/transwell). Values are means of six wells per fatty acid supplementation, with vertical lines representing standard errors of the mean. *Mean value was significantly different from that of the control supplementation $(P<0.05)$.
SCD and PPAR $\alpha$ mRNA were quantified using Assayon-Demand gene expression assays (Applied Biosystems, Warrington, Cheshire, UK). Oligonucleotide primers and Taq-Man probe sequences for SREBP-1c were as follows: forward- $5^{\prime}$ CCATGGATTGCACTTTCGAA $3^{\prime}$, reverse $-5^{\prime}$ CCAGCATAGGGTGGGTCAAA3', and probe-5'TATCAACAACCAAGACAGTGACTTCCCTGGC3' (as described in Sewter et al. 2002). The Taq-Man probe was labelled at the $5^{\prime}$ end with the reporter dye 6-carboxy-fluorescein and at the $3^{\prime}$ end with the quencher 6-carboxy-tetramethyl-rhodamine. Oligonucleotide primers and Taq-Man probes for the glyceraldehyde3-phosphate dehydrogenase, used as internal control, were purchased from Applied Biosystems. PCR was carried out in duplicate for each sample on an ABI 7700-sequence detection system (Applied Biosystems).

Each $25 \mu \mathrm{l}$ reaction mixture contained $2 \mu \mathrm{l}$ first-strand cDNA, 1X PCR master mix, 1.25 $\mu$ l Assay-on-Demand for SCD and PPAR $\alpha$ or SREBP-1c forward and reverse $(500 \mathrm{nmol} / \mathrm{l})$ and $250 \mathrm{nmol}$ SREBP-1c Taq-Man probe. All reactions were carried out using the following cycling parameters: $50^{\circ} \mathrm{C}$ for $2 \mathrm{~min}, 95^{\circ} \mathrm{C}$ for $10 \mathrm{~min}$, followed by forty cycles of $95^{\circ} \mathrm{C}$ for $15 \mathrm{~s}$ and $60^{\circ} \mathrm{C}$ for $1 \mathrm{~min}$.

After PCR, standard curves were constructed from the standard reactions for each target gene and internal control by plotting $\mathrm{Ct}$ values, i.e. the cycle number at which the fluorescence signal exceeds background $v$. log cDNA input (ng). The $\mathrm{Ct}$ readings for each of the unknown samples were then used to calculate the amount of either target or internal control relative to the standard. For each sample, results were normalised by dividing the amount of target by the amount of internal control. Repeatability of the PCR was examined by measuring the $\mathrm{Ct}$ readings of three samples.

\section{Fatty acid analysis}

Cells were washed twice with cold PBS, scraped into $15 \mathrm{ml}$ tubes, pelleted at $800 \mathrm{~g}$ for $5 \mathrm{~min}$ before being stored at $-80^{\circ} \mathrm{C}$. Total cellular lipids were extracted following the chloroform-methanol (1:1) procedure of Bligh \& Dyer (1959). As acid methylation induces isomerisation of CLA in a time- and temperature-correlated manner, the baseacid methylation parameters were optimised as previously described (Park et al. 2001) to minimise isomerisation of cis-trans bonds, artefact formation and to ensure that all fatty acids were methylated. The lipid extracts were dried under $\mathrm{N}_{2}$, converted to fatty acid methyl esters using $1 \mathrm{ml}$ $0.1 \mathrm{M}-\mathrm{KOH}-$ methanol at $70^{\circ} \mathrm{C}$ for $1 \mathrm{~h}$ followed by $0.4 \mathrm{ml}$ $1.2 \mathrm{M}-\mathrm{HCl}-$ methanol at $70^{\circ} \mathrm{C}$ for $15 \mathrm{~min}$ and extracted with hexane. The fatty acid methyl esters were separated by GC, conducted with a Thermo Finnigan Trace GC (Interscience, Milan, Italy) fitted with a flame ionisation detector and Chromquest 3.0 integrator (Thermo Finnigan, San Jose, CA, USA). A Restek RT-2560 (Bellefonte, PA, USA) fused silica capillary column $(100 \mathrm{~m} \times 0.25 \mathrm{~mm}$ internal diameter, $0.2 \mu \mathrm{m}$ film thickness) was used. The oven temperature was increased at $25^{\circ} \mathrm{C} / \mathrm{min}$ from 80 to $175^{\circ} \mathrm{C}$, and held for $25 \mathrm{~min}$. The temperature was then increased at $10^{\circ} \mathrm{C} / \mathrm{min}$ to $205^{\circ} \mathrm{C}$ and held for $4 \mathrm{~min}$. Finally, it was increased at $10^{\circ} \mathrm{C} / \mathrm{min}$ to $225^{\circ} \mathrm{C}$ and held for $20 \mathrm{~min} . \mathrm{H}_{2}$ was used as the carrier gas. The fatty acid methyl esters were identified 
by comparison with standards (Alltech Inc., Deerfield, IL, USA and Nu-Chek Prep Inc., Elysian, MN, USA).

\section{Statistical analysis}

Fatty acid data were analysed by the general linear model procedure of SAS (SAS Institute Inc., Cary, NC, USA). ANOVA was used to identify the effect of treatment and differences between treatment means were identified using the probability of difference option of the least significant means command. Two-way ANOVA was used to test the effect of fatty acid treatment (control, EPA and DSA), type of treatment (acute and acute-on-chronic) and their interaction term. Treatment effects and differences between means were considered significant when $P<0 \cdot 05$.

\section{Results}

\section{Cellular fatty acid composition}

The fatty acid composition of Caco-2 cells (Table 2) shows the most important changes occurred following the acute-onchronic rather than the acute fatty acid treatment. Acute-onchronic EPA treatment significantly $(P<0.05)$ reduced oleic acid levels, a product of SCD activity, but acute-on-chronic DSA treatment did not. Oleic acid was reduced following acute EPA and DSA treatments, but these changes were not significant. Both acute and acute-on-chronic EPA treatments significantly reduced TVA levels $(P<0 \cdot 01)$ and c9, t11-CLA levels $(P<0 \cdot 01)$. Acute and acute-on-chronic DSA treatments significantly reduced $\mathrm{c} 9$, t11-CLA only $(P<0 \cdot 01)$.

EPA was incorporated in cellular lipids and was elongated to 22: $5 n-3$, but was not desaturated into DHA (22: $6 n-3)$, following both acute and acute-on-chronic fatty acid treatments. Similar fatty acid profiles were observed in T84 cells (results not shown).

\section{Stearoyl-CoA desaturase desaturation index}

In both cell lines, the SCD desaturation index was defined as the oleic acid:oleic plus stearic acids ratio. The SCD desaturation index was not affected by any acute treatment, but the acute-on-chronic treatment with EPA, and to a lesser extent with DSA, reduced the desaturation levels of stearic acid (Fig. 2(A)). Supplementation of the nutritive media with EPA also reduced the desaturation of TVA but the acute treatment did not (Fig. 2(B)). Both acute and acute-on-chronic exposures with DSA reduced SCD desaturation indices. The effects were similar on both cell lines but, in T84, the desaturation of TVA was lower. SCD desaturation of TVA is quickly inhibited by DSA during the acute treatment, even after $1 \mathrm{~h}$ (results not shown), which suggests that DSA acts directly on the enzyme. To obtain inhibition of SCD by EPA, a longer duration was required, which suggests an effect limited to the transcription level. In both cell lines, the two-way ANOVA analysis on desaturation indices indicated that fatty acid treatment, type of treatment and their interaction were highly significant $(P<0 \cdot 01)$; this illustrates

Table 2. Caco-2 cell fatty acid composition ( $\mu \mathrm{mol} / \mathrm{g}$ cellular protein) following acute or acute-on-chronic treatment with eicosapentaenoic acid or 3,10-dithia stearic acid (DSA)

(Mean values with their standard errors of three inserts cultured in parallel)

\begin{tabular}{|c|c|c|c|c|c|c|c|c|c|c|c|c|}
\hline & \multicolumn{6}{|c|}{ Acute } & \multicolumn{6}{|c|}{ Acute-on-chronic } \\
\hline & \multicolumn{2}{|c|}{ Control } & \multicolumn{2}{|c|}{ EPA } & \multicolumn{2}{|c|}{ DSA } & \multicolumn{2}{|c|}{ Control } & \multicolumn{2}{|c|}{ EPA } & \multicolumn{2}{|c|}{ DSA } \\
\hline $10: 0$ & 2.50 & 0.57 & $2 \cdot 28$ & $0 \cdot 16$ & $2 \cdot 15$ & 0.51 & 1.97 & 0.20 & $2 \cdot 89$ & 1.37 & $1 \cdot 72$ & 0.40 \\
\hline $12: 0$ & $3 \cdot 10$ & 0.59 & 2.65 & 0.42 & $2 \cdot 62$ & 0.73 & 2.49 & 0.16 & $2 \cdot 79$ & $1 \cdot 21$ & $2 \cdot 44$ & 0.67 \\
\hline $14: 0$ & $18 \cdot 63$ & $2 \cdot 76$ & $16 \cdot 91$ & 1.45 & $17 \cdot 40$ & $3 \cdot 22$ & $16 \cdot 75$ & 0.34 & $16 \cdot 79$ & $1 \cdot 28$ & $14 \cdot 31$ & 3.43 \\
\hline $16: 1$ t9 & $<0.01$ & & $<0.01$ & & $<0.01$ & & $<0.01$ & & $<0.01$ & & $<0.01$ & \\
\hline $16: 1 c 9$ & $87 \cdot 18$ & $13 \cdot 47$ & $75 \cdot 56$ & 8.08 & $72 \cdot 28$ & $6 \cdot 86$ & $72 \cdot 79$ & $3 \cdot 28$ & $44 \cdot 65^{\star \star}$ & 3.73 & $60 \cdot 37$ & $7 \cdot 71$ \\
\hline $17: 0$ & 1.08 & $0 \cdot 10$ & 1.62 & $0 \cdot 75$ & 1.95 & $1 \cdot 20$ & 0.76 & 0.13 & $1 \cdot 17$ & 0.61 & 0.87 & 0.10 \\
\hline $18: 0$ & $142 \cdot 13$ & $19 \cdot 05$ & $119 \cdot 49$ & $8 \cdot 51$ & $115 \cdot 18$ & $12 \cdot 23$ & $115 \cdot 96$ & 3.09 & $110 \cdot 34$ & $3 \cdot 82$ & $121 \cdot 64$ & $13 \cdot 27$ \\
\hline $18: 1 \mathrm{t} 9$ & $<0.01$ & & $<0.01$ & & $<0.01$ & & $<0.01$ & & $<0.01$ & & $<0.01$ & \\
\hline $18: 1 t 11$ & $35 \cdot 76$ & $5 \cdot 88$ & $15 \cdot 45^{\star}$ & 1.88 & 28.01 & $2 \cdot 55$ & $30 \cdot 13$ & $1 \cdot 70$ & $17 \cdot 46^{\star \star}$ & 0.58 & $25 \cdot 88$ & 4.08 \\
\hline $18: 1 c 9$ & $285 \cdot 64$ & 41.4 & $239 \cdot 06$ & $22 \cdot 3$ & 224.72 & $23 \cdot 7$ & 231.01 & $10 \cdot 3$ & $168 \cdot 12^{\star *}$ & $9 \cdot 2$ & $200 \cdot 27$ & $24 \cdot 2$ \\
\hline $18: 1 c 11$ & $101 \cdot 10$ & $14 \cdot 1$ & 83.98 & $7 \cdot 85$ & $81 \cdot 30$ & $8 \cdot 82$ & $77 \cdot 28$ & $2 \cdot 42$ & $55 \cdot 83^{\star \star}$ & 4.03 & $59 \cdot 11^{*}$ & $7 \cdot 89$ \\
\hline $20: 0$ & 5.93 & 0.54 & $4 \cdot 84$ & 0.33 & $4 \cdot 60$ & 0.56 & 5.09 & 0.41 & $2 \cdot 72^{\star \star}$ & 0.41 & 4.97 & 0.71 \\
\hline $18: 3 n-3$ & 2.67 & 0.38 & $2 \cdot 73$ & 0.20 & $2 \cdot 56$ & 0.38 & $2 \cdot 36$ & $1 \cdot 18$ & $4 \cdot 25$ & 0.23 & $5 \cdot 42$ & 1.66 \\
\hline $18: 2 c 9 t 11$ & $16 \cdot 97$ & 2.55 & $7 \cdot 68^{*}$ & 0.92 & $3.53^{\star *}$ & 0.36 & $12 \cdot 15$ & 0.32 & $4 \cdot 35^{\star \star}$ & 0.42 & $4 \cdot 26^{\star \star}$ & 0.66 \\
\hline $18: 2 \mathrm{t} 10 \mathrm{c} 12$ & $<0.01$ & & $<0.01$ & & $<0.01$ & & $<0.01$ & & $<0.01$ & & $<0.01$ & \\
\hline $20: 3 n-6$ & $8 \cdot 38$ & $1 \cdot 21$ & $6 \cdot 71$ & 0.43 & 6.55 & 0.65 & $6 \cdot 41$ & 0.23 & 5.56 & 0.37 & $6 \cdot 41$ & 0.84 \\
\hline $20: 4 n-6$ & 34.80 & $5 \cdot 83$ & 21.53 & $9 \cdot 68$ & $28 \cdot 11$ & $2 \cdot 87$ & $26 \cdot 01$ & 0.63 & $24 \cdot 21$ & $2 \cdot 18$ & $25 \cdot 85$ & $2 \cdot 88$ \\
\hline $20: 5 n-3$ & $4 \cdot 76$ & 0.58 & $90 \cdot 65^{\star *}$ & 9.53 & $4 \cdot 22$ & 0.25 & 3.77 & 0.30 & $117 \cdot 79^{* *}$ & $11 \cdot 6$ & 3.61 & 0.23 \\
\hline $22: 5 n-3$ & 13.46 & 1.76 & $21 \cdot 71^{*}$ & 2.09 & $10 \cdot 26$ & $1 \cdot 10$ & $10 \cdot 21$ & 0.49 & $76 \cdot 50^{\star * *}$ & $6 \cdot 38$ & $10 \cdot 22$ & 1.68 \\
\hline $22: 6 n-3$ & 14.04 & $2 \cdot 29$ & $11 \cdot 32$ & $1 \cdot 17$ & $11 \cdot 14$ & $1 \cdot 11$ & $10 \cdot 58$ & 0.10 & 8.97 & $0 \cdot 78$ & $10 \cdot 46$ & $1 \cdot 24$ \\
\hline
\end{tabular}

Mean value was significantly different from that of the control: ${ }^{*} P<0.05$; ${ }^{* *} P<0.01$. 

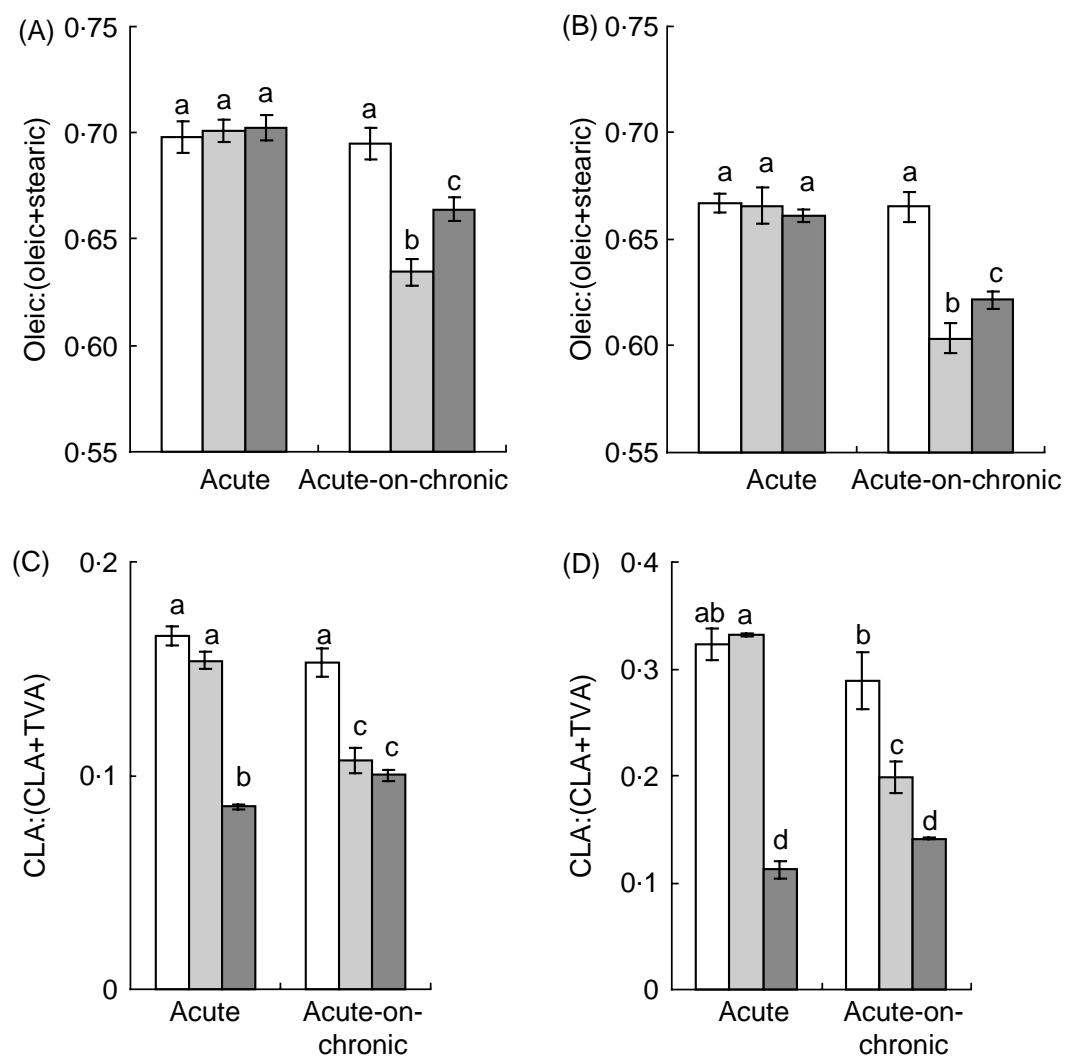

Fig. 2. Effect of acute and acute-on-chronic exposures to EPA ( $\square$ ) or 3,10-dithia stearic acid ( $\square$ ) on fatty acid stearoyl-CoA desaturase (SCD) indices in T84 $(A$ and $C)$ and Caco-2 (B and D) cells compared with control $(\square)$. Indices are defined as the ratio of SCD product:(SCD product + substrate). (A and B) Oleic acid:(oleic acid + stearic acid); (C and D) cis9, trans11-conjugated linoleic acid (CLA):(cis9, trans11-CLA + trans-vaccenic acid (TVA)). Values are means of three different inserts cultured in parallel, with vertical lines representing standard deviations. ${ }^{a, b, c, d}$ Mean values with unlike letters were significantly different $(P<0.05)$.

that acute-on-chronic treatment had more profound effects on fatty acid composition compared with acute treatment alone.

\section{Stearoyl-CoA desaturase mRNA abundance}

In both cell lines, the acute EPA and DSA treatments did not alter SCD mRNA levels ((Fig. 3(A) and Fig. 3(B)). In contrast acute-on-chronic EPA supplementation induced a marked decrease in SCD mRNA levels in Caco-2 cells (1.27 (SD 0.23) v. 0.74 (SD 0.05); $P<0.05$ ). But acute-on-chronic DSA supplementation did not. This effect of EPA may explain the effect observed on the desaturation index following EPA acute-on-chronic condition as presented in Fig. 2. EPA supplementation also reduced SCD mRNA levels in T84 cells. In contrast, DSA supplementation significantly increased SCD mRNA levels in T84 cells.

mRNA levels of stearoyl-CoA desaturase transcription factors: sterol regulatory-element binding protein-1c and peroxisome proliferator-activated receptor $\alpha$

The transcription of SCD is under the control of two transcription factors, SREBP-1c and PPAR $\alpha$ (Nakamura \& Nara, 2002). We investigated whether the mRNA levels of SREBP$1 \mathrm{c}$ or PPAR $\alpha$ was altered by acute or acute-on-chronic administrations of EPA or DSA. In our experiments, the transcription of SREBP-1c was reduced by the acute-on-chronic fatty acid interventions (Fig. 3(C)), but the decrease by DSA was lower than that observed with EPA. No differences in mRNA levels of PPAR $\alpha$ (Fig. 3(D)) were observed for any exposure. Neither SREBP-1c nor PPAR $\alpha$ mRNA levels were altered by acute treatments with EPA or DSA (results not shown).

\section{Discussion}

TVA is the precursor of c9, t11-CLA, a fatty acid that has been associated with potential anti-carcinogenic, anti-diabetic, anti-inflammatory and cardioprotective effects (Belury, 2002; Roche et al. 2002; Toomey et al. 2003; Field \& Schley, 2004; McLeod et al. 2004; O'Shea et al. 2004; Wang \& Jones, 2004). We addressed the hypothesis that intestinal TVA absorption and biotransformation into CLA can be modulated by other nutrients or xenobiotics. Therefore, the present study aimed at investigating whether TVA is metabolised in differentiated intestinal cells and determined whether intestinal TVA metabolism can be modified by PUFA.

The enzyme SCD (also referred to as $\Delta$ 9-desaturase; EC $1 \cdot 14.99 .5)$ catalyses the insertion of a cis double bond in ninth position in the carbon chain of saturated and unsaturated fatty acids, including TVA. It has been suggested that several nutrients (PUFA and fructose), drugs (thia fatty acids and sterculic acid) and hormones (insulin and leptin) modulate SCD expression and activity, as reviewed in Ntambi \& Miyazaki (2004). Moreover mouse in vivo studies (Loor et al. 2002, 

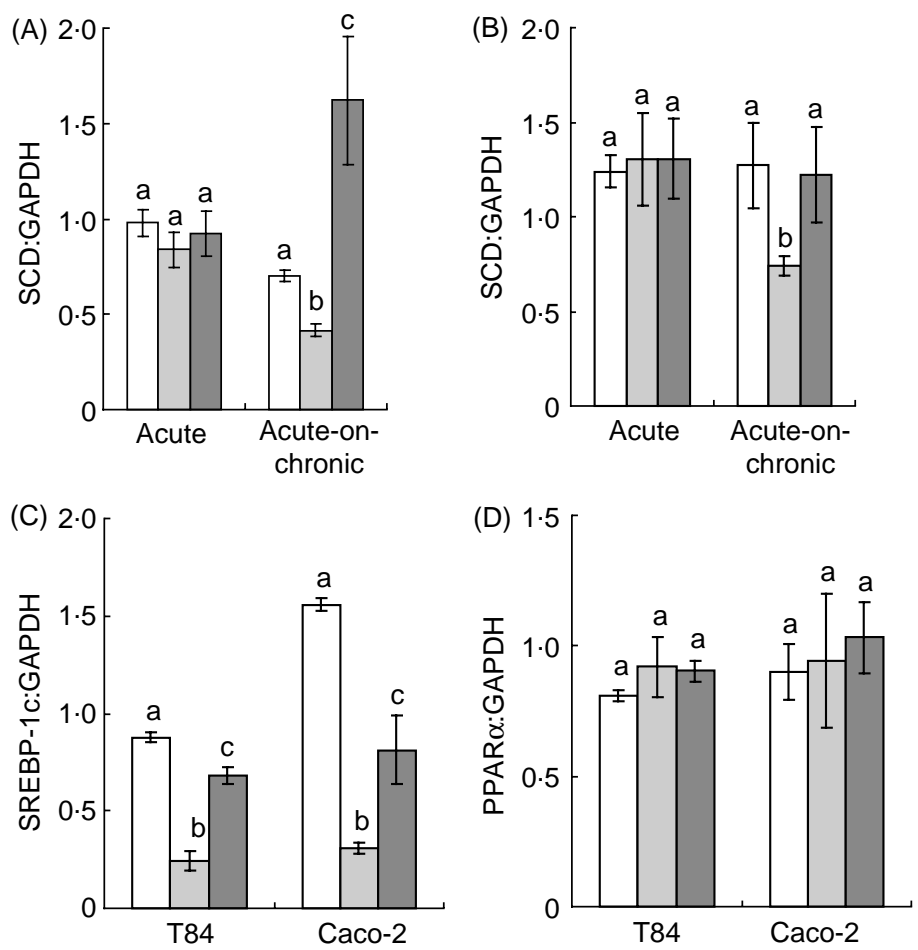

Fig. 3. Effect of acute and acute-on-chronic treatment with EPA ( $\square$ ) or 3,10-dithia stearic acid $(\square)(7 \mathrm{~d}$ with $0.03 \mathrm{~mm}$ followed by $3 \mathrm{~h}$ with $0.3 \mathrm{~mm})$ on stearoyl-CoA desaturase (SCD) mRNA levels (Ct values normalised on Ct values of GAPDH) in T84 (A) and Caco-2 (B) cells and effect of acute-on-chronic treatment on sterol regulatory-element binding protein-1c (SREBP-1c) (C) or PPAR $\alpha$ (D) mRNA levels in T84 and Caco-2 cells. Values are means of three different inserts cultured in parallel, with vertical lines representing standard deviations. ${ }^{a, b, c}$ Mean values with unlike letters were significantly different $(P<0 \cdot 05)$.

2003; Lin et al. 2004) demonstrated that TVA metabolism can be modulated by diet composition. The present study focused on the effect of EPA on SCD mRNA levels and TVA metabolism because preliminary work in Caco-2 cells demonstrated that EPA was the most effective PUFA to reduce SCD desaturation indices in Caco-2 cells (B Renaville, YJ Schneider and Y Larondelle, unpublished results). In addition, the metabolic effects of DSA, a known pharmacological inhibitor of SCD (Hovik et al. 1997), were investigated in order to act as a comparison to the natural fatty acid EPA.

In vivo studies demonstrated that desaturation indices do not always reflect enzyme activity (Archibeque et al. 2005), in part because ingestion of SCD substrates and products may vary between diets. Nevertheless, in our in vitro model, SCD substrate fatty acid supply was constant, therefore desaturation products could not be derived from other fatty acid sources. Hence we propose that the SCD desaturation index could be ascribed to different SCD activity, albeit a surrogate marker for SCD activity. Overall the present results showed that acute EPA and DSA treatments were insufficient to cause consistent changes in SCD mRNA levels, SCD activity on oleic acid and alter fatty acid composition, in comparison with the acute-on-chronic effect of fatty acid interventions. This is probably related to insufficient time for the fatty acids to induce important effects, as previously observed (Black et al. 2002b). Neither acute EPA nor DSA reduced oleic acid levels and oleic desaturation indices. Acute DSA treatment significantly reduced CLA levels and desaturation indices. Whilst acute EPA treatment reduced CLA concentration, it had no effect on the SCD desaturation index, an effect which may be ascribed to altered TVA absorption. Acute-on-chronic EPA reduced TVA, oleic and CLA concentrations, which were associated with lower SCD desaturation indices and lower SCD and SREBP-1c mRNA levels. This discrepancy between acute and acute-on-chronic EPA effects probably reflects the cumulative effect of fatty acid exposure over time (Black et al. 2002b). The chronic effect of EPA on SREBP-1c mRNA levels in Caco-2 cells agrees with previous work (Field et al. 2002). Since the transcription factor SREBP-1c regulates SCD gene transcription, we suggest that the effect of EPA on SCD mRNA levels was mediated by SREBP-1c. We propose that lowered levels of SREBP-1c would decrease SCD gene transcription and expression, which would in turn decrease the SCD activity on TVA.

The effects of DSA were different from those of EPA. Furthermore, DSA had different effects in the two cell lines studied. In Caco-2 cells, acute treatment and acute-on-chronic supplementation with DSA significantly reduced SCD desaturation indices and CLA concentrations, but did not alter SCD mRNA levels, suggesting that DSA directly acts on SCD at the protein level, reducing the desaturation of TVA by competition, as suggested by Hovik et al. (1997). In T84 cells, again both types of treatment significantly reduced SCD desaturation indices. However, the acute-on-chronic DSA condition increased SCD mRNA levels in T84 cells. The differential effect of DSA on transcription and translation could be related to time-related differences in the expression and activity of SCD, between the two cell lines used. Otherwise the thia group in third position of the chain is known to activate SCD transcription (Madsen et al. 1997), whereas 
the tenth sulfur substitute to methylene is known to inhibit the activity of SCD (Hovik et al. 1997), which could be related to the opposite effects of DSA on activity and transcription of SCD in T84 cells. Acute-on-chronic DSA treatment also reduced SREBP-1c mRNA levels but this was not associated with lower SCD mRNA levels. This implies that lower SREBP-1c mRNA levels were insufficient to alter or were not correlated with transcriptional activity. PPAR $\alpha$ is a key transcription factor that regulates fatty acid oxidation, especially in the liver. Given the regulatory relationship between SCD and PPAR $\alpha$, we determined whether alterations in SCD mRNA levels could be explained by differential intestinal PPAR $\alpha$ mRNA levels. In the present study, neither EPA nor DSA had any effect on the PPAR $\alpha$ mRNA levels.

Nutritionists may recommend increased consumption of c9, t11-CLA and long-chain PUFA. The production costs of pure c9, t11-CLA supplements are prohibitive, therefore naturally enriched CLA meat and dairy products, containing c9, t11CLA and its precursor TVA, could become a good alternative to fatty acid supplementation (Corl et al. 2003). The research presented here in relation to the intestinal desaturation of TVA is highly relevant within the context of any potential health benefits of food sources of TVA and CLA. The results suggest that EPA could decrease the positive effects of TVA, by inhibiting its intestinal desaturation, illustrating once again the potential interactions between nutrients at the intestinal level.

\section{Acknowledgements}

The authors thank Professor Spydevold for supplying the DSA. The authors are grateful to Ana Terres for providing the cells and useful advice for cell culture. B. R. is a fellow of the FRIA (Belgium) and the stay of B. R. in the Nutrigenomics laboratory was funded by the French Community of Belgium.

\section{References}

Archibeque SL, Lunt DK, Gilbert CD, Turner RK \& Smith SB (2005) Fatty acid indices of stearoyl-CoA desaturase do not reflect actual stearoyl-CoA desaturase enzyme activities in adipose tissues of beef steers finished with corn-, flaxseed-, or sorghum-based diets. J Anim Sci 83, 1153-1166.

Astorg P, Arnault N, Czernichow S, Noisette N, Galan P \& Hercberg S (2004) Dietary intakes and food sources of $n-6$ and n-3 PUFA in French adult men and women. Lipids 39, 527-535.

Belury MA (2002) Dietary conjugated linoleic acid in health: physiological effects and mechanisms of action. Annu Rev Nutr 22, $505-531$.

Black IL, Roche HM \& Gibney MJ (2002a) Acute and chronic effects of conjugated linoleic acid (CLA) isomers (trans-10, cis-12 CLA and cis-9, trans-11 CLA) on human colon carcinoma (Caco-2) cell line lipid metabolism. $J$ Nutr 132, 2167-2173.

Black IL, Roche HM, Tully AM \& Gibney MJ (2002b) Acute-onchronic effects of fatty acids on intestinal triacylglycerol-rich lipoprotein metabolism. Br J Nutr 88, 661-669.

Bligh EG \& Dyer WJ (1959) A rapid method of total lipid extraction and purification. Can J Biochem Physiol 37, 911-917.

Corl BA, Barbano DM, Bauman DE \& Ip C (2003) Cis-9, trans-11 CLA derived endogenously from trans-11-18:1 reduces cancer risk in rats. $J$ Nutr 133, 2893-2900.
Field CJ \& Schley PD (2004) Evidence for potential mechanisms for the effect of conjugated linoleic acid on tumor metabolism and immune function: lessons from n-3 fatty acids. Am J Clin Nutr 79, 1190S-1198S.

Field FJ, Born E, Murthy S \& Mathur SN (2002) Polyunsaturated fatty acids decrease the expression of sterol regulatory element-binding protein- 1 in $\mathrm{CaCo}-2$ cells: effect on fatty acid synthesis and triacylglycerol transport. Biochem $J \mathbf{3 6 8}$, $855-864$.

Gruffat D, De La Torre A, Chardigny JM, Durand D, Loreau O \& Bauchart D (2005) Vaccenic acid metabolism in the liver of rat and bovine. Lipids 40, 295-301.

Hovik KE, Spydevold OS \& Bremer J (1997) Thia fatty acids as substrates and inhibitors of stearoyl-CoA desaturase. Biochim Biophys Acta 1349, 251-256.

Kim YC \& Ntambi JM (1999) Regulation of stearoyl-CoA desaturase genes: role in cellular metabolism and preadipocyte differentiation. Biochem Biophys Res Commun 266, 1-4.

Lin X, Loor JJ \& Herbein JH (2004) Trans10,cis12-18:2 is a more potent inhibitor of de novo fatty acid synthesis and desaturation than cis9,trans11-18:2 in the mammary gland of lactating mice. J Nutr 134, 1362-1368.

Lock AL, Corl BA, Barbano DM, Bauman DE \& Ip C (2004) The anticarcinogenic effect of trans-11 18:1 is dependent on its conversion to cis-9, trans-11 CLA by delta 9-desaturase in rats. J Nutr 134, 2698-2704.

Loor JJ, Lin X \& Herbein JH (2002) Dietary trans-vaccenic acid (trans11-18:1) increases concentration of cis9,trans11-conjugated linoleic acid (rumenic acid) in tissues of lactating mice and suckling pups. Reprod Nutr Dev 42, 85-99.

Loor JJ, Lin X \& Herbein JH (2003) Effects of dietary cis 9, trans 11-18:2, trans 10 , cis 12-18:2, or vaccenic acid (trans 11-18:1) during lactation on body composition, tissue fatty acid profiles, and litter growth in mice. Br J Nutr 90, 1039-1048.

McLeod RS, LeBlanc AM, Langille MA, Mitchell PL \& Currie DL (2004) Conjugated linoleic acids, atherosclerosis, and hepatic very-low-density lipoprotein metabolism. Am J Clin Nutr 79, 1169S-1174S.

Madsen L, Froyland L, Grav HJ \& Berge RK (1997) Up-regulated delta 9-desaturase gene expression by hypolipidemic peroxisomeproliferating fatty acids results in increased oleic acid content in liver and VLDL: accumulation of a delta 9-desaturated metabolite of tetradecylthioacetic acid. J Lipid Res 38, 554-563.

Nakamura MT \& Nara TY (2002) Gene regulation of mammalian desaturases. Biochem Soc Trans 30, 1076-1079.

Ntambi JM (1999) Regulation of stearoyl-CoA desaturase by polyunsaturated fatty acids and cholesterol. $J$ Lipid Res 40, $1549-1558$.

Ntambi JM \& Miyazaki M (2004) Regulation of stearoyl-CoA desaturases and role in metabolism. Prog Lipid Res 43, 91-104.

O'Shea M, Bassaganya-Riera J \& Mohede IC (2004) Immunomodulatory properties of conjugated linoleic acid. Am J Clin Nutr 79, 1199S-1206S.

Park Y, Albright KJ, Cai ZY \& Pariza MW (2001) Comparison of methylation procedures for conjugated linoleic acid and artifact formation by commercial (trimethylsilyl) diazomethane. J Agric Food Chem 49, 1158-1164.

Roche HM, Noone E, Sewter C, McBennett S, Savage D, Gibney MJ, O'Rahilly S \& Vidal-Puig AJ (2002) Isomer-dependent metabolic effects of conjugated linoleic acid: insights from molecular markers sterol regulatory element-binding protein-1c and LXRalpha. Diabetes 51, 2037-2044.

Sessler AM, Kaur N, Palta JP \& Ntambi JM (1996) Regulation of stearoyl-CoA desaturase-1 mRNA stability by polyunsaturated fatty acids in 3T3-L1 adipocytes. $J$ Biol Chem 271, 29854-29858. 
Sewter C, Berger D, Considine RV, et al. (2002) Human obesity and type 2 diabetes are associated with alterations in SREBP1 isoform expression that are reproduced ex vivo by tumor necrosis factoralpha. Diabetes 51, 1035-1041.

Slattery ML, Benson J, Ma KN, Schaffer D \& Potter JD (2001) Transfatty acids and colon cancer. Nutr Cancer 39, 170-175.

Sommerfeld M (1983) Trans unsaturated fatty acids in natural products and processed foods. Prog Lipid Res 22, 221-233.
Toomey S, Roche H, Fitzgerald D \& Belton O (2003) Regression of pre-established atherosclerosis in the apoE-/- mouse by conjugated linoleic acid. Biochem Soc Trans 31, 1075-1079.

Wang Y \& Jones PJ (2004) Dietary conjugated linoleic acid and body composition. Am J Clin Nutr 79, 1153S-1158S.

Wolff RL (1995) Content and distribution of trans-18:1 acids in ruminant milk and meat fats. Their importance in European diets and their effect on human milk. J Am Oil Chem Soc 72, 259-272. 